\title{
Sensitivity of lymphocytes from patients with systemic lupus erythematosus to the induction of sister chromatid exchanges by alkylating agents and bromodeoxyuridine
}

\author{
R G PALMER, 'CAROLINE A SMITH-BURCHNELL,' \\ CAROLINE J DORÉ, ${ }^{2}$ AND A M DENMAN ${ }^{1}$
}

From the 'Connective Tissue Disease Research Group and 'Division of Medical Statistics, Clinical Research Centre, Watford Road, Harrow, Middlesex

SUMmARY Several authors have suggested that the cells of patients with systemic lupus erythematosus (SLE) have defects of DNA repair. Cells from patients with the classical chromosomal instability syndromes, thought to be due to defects in DNA repair, are hypersensitive to the chromosome damaging effects of some DNA damaging agents, measured as sister chromatid exchange (SCE). We have observed that lymphocytes of patients with SLE are not more sensitive than lymphocytes from healthy individuals to the SCE inducing effects of the DNA damaging agents methyl nitrosourea, methyl methanesulphonate, chlorambucil, and $\vec{\oplus}$ bromodeoxyuridine. These observations do not support the suggestion that cells of patients wit SLE have an underlying defect of DNA repair.

Several authors have considered the possibility of a defect of DNA repair in lymphocytes of patients with systemic lupus erythematosus (SLE); it has been claimed that these cells have impaired repair of DNA damage induced by ultraviolet (UV) light and methyl nitrosourea (MNU). ${ }^{1-4}$ Indeed, patients with this disease have some clinical features, especially the sensitivity to sunlight and immunological abnormalities, that are similar to those found in patients with the classical chromosomal instability syndromes. These conditions have characteristic abnormalities of DNA repair. For example, patients with Bloom's syndrome may develop skin rashes induced and exacerbated by sunlight. This condition was originally described by the title "congenital telangiectatic erythema resembling lupus erythematosus in dwarfs'. ${ }^{\prime}$ These patients also have defects of cell mediated immunity and immunoglobulin synthesis. The most striking feature of xeroderma pigmentosum is hypersensitivity of skin to sunlight, and patients with ataxia telangiectasia and Fanconi's anaemia have been considered to have some defects of humoral and cell mediated immunity. ${ }^{78}$ Unlike

Accepted for publication 14 July 1986.

Correspondence to Dr R G Palmer, Clinical Research Centre, Watford Road, Harrow, Middlesex HAl 3UJ.
SLE these syndromes are associated with a high incidence of malignancy.

Cells from patients with the chromosomal instability syndromes are hypersensitive to the chromosome damaging effects of some DNA damaging agents, including cytotoxic drugs. This effect can be detected by counting sister chromatid exchanges (SCEs). In Bloom's syndrome a very high background SCE frequency is found in cultured lymphocytes, ${ }^{9}$ fibroblasts, ${ }^{10}$ and bone marrow cells. " Methyl nitrosourea increases counts to a greater degree in these cells than in normal cells. ${ }^{12}$ 의 Similarly, xeroderma pigmentosum cells show an 0 enhanced SCE response to a wide range of genotoxic chemicals, including alkylating agents, ${ }^{13}$ and $\frac{D}{O}$ Fanconi's anaemia cells have been reported to be hypersensitive to the cross linking cytotoxic drug or mitomycin $\mathrm{C}^{14}$ Cells from patients with ataxia $\sim$ telangiectasia are hypersensitive to the cytotoxic N drug bleomycin. ${ }^{15}$ It is reasonable to presume that ${ }^{\omega}$ individuals with these syndromes would be hypersensitive in vivo to the effects of some cytotoxic $\stackrel{\circ}{=}$ drugs and be more likely to develop further chromo- $\Phi$ some abnormalities, and possibly malignancies, than individuals receiving these drugs whose chromo- $\frac{T}{0}$ somes did not possess inherent abnormalities. Little $\underset{\mathbb{D}}{\stackrel{0}{ }}$ is known about this possibility except that patients $\frac{\rho}{\mathbb{Q}}$ 
with ataxia telangiectasia may be unduly sensitive to $x$ irradiation. $^{16}$

Spontaneous SCE frequencies are raised in blood lymphocytes of patients with SLE; $;^{17}$ the SCEs of SLE fibroblasts are normal. ${ }^{18}$ If cells from these patients have defects of DNA repair, it is possible that these individuals would also be hypersensitive to the chromosome damaging effects of some cytotoxic drugs. In vivo it is not known if patients with SLE are more likely to develop drug induced malignancies than patients with other conditions who receive these drugs. It is possible, however, to determine the in vitro sensitivity of cells from patients with SLE to the chromosome damaging effects of cytotoxic drugs. We report our observations on SCEs induced by the experimental alkylating agents methyl nitrosourea (MNU) and methyl methanesulphonate (MMS), the therapeutic alkylating agent chlorambucil, and the thymidine analogue bromodeoxyuridine (BUdR).

\section{Patients and methods}

\section{PATIENTS}

All patients with SLE fulfilled the American Rheumatism Association criteria for this disease. ${ }^{19}$ Healthy individuals served as controls. Five patients with SLE and five controls were used for the MNU and chlorambucil experiments and two patients with SLE and two controls were used for the MMS and BUdR experiments. Different patients and controls were used for each experiment.

\section{METHODS}

Metaphase spreads demonstrating SCEs were prepared from whole blood cultures by the variation of Goto et $a l^{20}$ of the fluorescence plus Giemsa technique of Perry and Wolff. ${ }^{21}$ Specific details and examples of SCEs have already been published. ${ }^{22}$ In brief, $0.5 \mathrm{ml}$ of heparinised whole blood was added to $6 \mathrm{ml}$ of RPMI culture medium containing $10 \%$ fetal calf serum, buffer, and antibiotics. MNU $(0 \cdot 2$ $\mathrm{mmol} / \mathrm{l})$ or MMS $(0.2 \mathrm{mmol} / \mathrm{l})$ was present for the first hour of culture before cells were washed twice by centrifugation in fresh culture medium. Phytohaemagglutinin $(0 \cdot 1 \mathrm{ml}$ reagent grade) was then added. Other cultures were incubated with varying concentrations of chlorambucil for two hours before washing and the addition of phytohaemagglutinin. Twenty four hours later the cells were incubated with BUdR. In one experiment varying concentrations of BUdR were used; in all others the final concentration of BUdR was $30 \mu \mathrm{mol} / \mathrm{l}$. For the last two hours of the 72 hour culture period colchicine was present. Slide preparations of metaphase spreads were stained with Hoescht 33258 fluorescent stain, exposed to UV light, and finally stained with Giemsa. The SCEs of 20 metaphases were counted from coded samples.

STATISTICAL ANALYSIS

The SCE results were not 'normally distributed' and the most appropriate form of data transformation was sought. Transformations considered were none, square root, $\log$, and $\log (\mathrm{SCE}+1)$. Each culture was considered to be an experimental unit. The chemical agent with the largest number of experimental units was chlorambucil (five patients and five controls, four concentrations of drug). The strategy adopted was to determine which transformation appeared to be the most appropriate for this agent and then to determine whether the same transformation was acceptable for the other agents. The most weight was given to Tukey's test of additivity $^{23}$ (which assesses parallelism of the concentration response between individuals) for between experimental unit variation. We also tried to achieve 'normality' for the within experimental unit variation so that the most appropriate summary measure of the centre of the distribution was used. The best transformation for chlorambucil applying these criteria was the square root. This also gave reasonable results for both $\mathrm{MNU}$ and BUdR. There

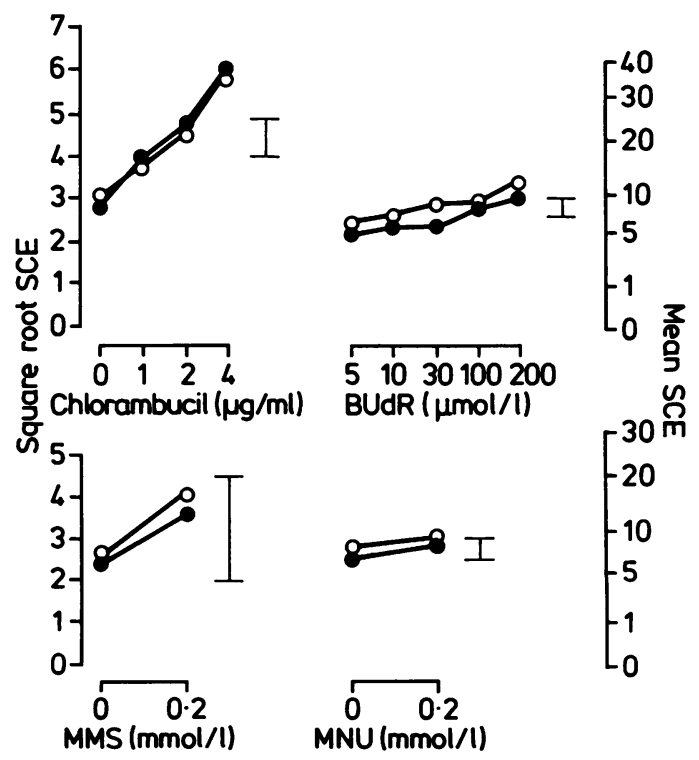

FIG. 1 Effects of alkylating agents and BUdR on SCE frequencies. $=$ normal; $O=S L E$. Vertical bars $=95 \%$ confidence interval for difference between any normal and $S L E$ concentration mean on square root axis. 
Table 1 Analysis of variance: $p$ values

\begin{tabular}{llll}
\hline & Group & Concentration & Group $\times$ concentration \\
\hline MNU & 0.4 & $<0.01$ & 0.6 \\
MMS & $0 \cdot 6$ & $<0 \cdot 05$ & 0.7 \\
Chlorambucil & 0.9 & $<0.0001$ & 0.9 \\
BUdR & $0 \cdot 1$ & $<0.0001$ & $0 \cdot 1$ \\
\hline
\end{tabular}

was marginally significant $(p=0 \cdot 03)$ non-additivity for MMS. but as there were only eight experimental units in this study, this was not considered to be important. Data for each chemical agent were square root transformed and two way analysis of variance performed on the means of each experimental unit.

\section{Results}

The mean values for each agent are shown in Fig. 1, and results of the analysis of variance are summarised in Table 1. The factors included were group (normal or SLE), concentration of chemical agent, and group $\times$ concentration interaction. There was a significant effect of concentration for all agents. There were no significant differences between the normal and SLE groups for any agent. There were no significant interactions between group and concentration, indicating that the difference between normal and SLE cells did not vary with the concentration of agents used.

\section{Discussion}

Lymphocytes from patients with SLE are not more sensitive than the lymphocytes from healthy individuals to the SCE inducing effects of MNU, MMS, chlorambucil, and BUdR. Published data on SCE responses of SLE cells to chemical agents that damage DNA are limited. One report showed that the SCE response of SLE cells to mitomycin C is normal. ${ }^{17}$ It is likely that SLE cells have a normal capacity for repairing damage to DNA induced by these agents.

It has been reported that SLE lymphocytes are less able to survive in the presence of MNU than lymphocytes from healthy controls, suggesting that cells from patients with SLE are less proficient than normal cells at removing the abnormal base $O^{6}$. methylguanine induced by this compound. ${ }^{4} \mathrm{We}$ have observed that the SCE response of SLE lymphocytes to MNU is normal. Therefore, contrary to one report, ${ }^{24} O^{6}$-methylguanine is unlikely to be the lesion responsible for the formation of SCEs.
Data concerning DNA repair in SLE cells after non-chemical damage such as that induced by UV light are also limited and conflicting. In one study lymphocytes from patients with SLE 'in remission' were found to have less unscheduled DNA synthesis, a measure of DNA repair, after exposure to UV light than control lymphocytes. ${ }^{3}$ In contrast, unscheduled DNA synthesis in lymphocytes from patients 'in exacerbation' was increased. The terms 'remission' and 'exacerbation' were not defined. Others have found that unscheduled DNA synthesis was normal on exposure to UV light of lymphocytes of patients with discoid lupus erythematosus. ${ }^{2}$ Fibroblasts from patients with SLE repair proficiently the damage to DNA induced by UV light. ${ }^{25}$

Spontaneous SCE frequencies in lymphocytes of untreated SLE patients are higher than those of controls. ${ }^{17} 18$ It has not been possible for us to demonstrate this effect clearly with the small numbers of patients in this limited further study.

We have shown that the SCEs of normal and SLE lymphocytes increase with the concentration of $\frac{\mathbb{O}}{2}$ chlorambucil and BUdR in the medium. Others have also demonstrated a positive dose response with these compounds in vitro. ${ }^{26}{ }^{27}$ MNU and MMS $\overrightarrow{0}$ are well known inducers of SCEs. ${ }^{28} 29$

In conclusion we have shown that lymphocytes from patients with SLE and from healthy controws are equally sensitive to the SCE inducing effects of the alkylating agents MNU, MMS, and chlorambucil, and the thymidine analogue BUdR. These $\stackrel{\odot}{\Phi}$ observations do not support the suggestion that cells of patients with SLE have an underlying defect of DNA repair, at least with respect to damage by these agents. It remains to be established that in vivo patients with SLE are no more sensitive than individuals with other diseases to the chromosome damage induced by therapeutic alkylating agents and other cytotoxic drugs.

\section{References}

1 Altmann H. DNA-repair and mutations in immunocompetent cells from patients with rheumatic diseases and corresponding 음 animal models. Studia Biophysica (Berlin) 1977; 61: 89-96.

2 Horkay I, Nagy E, Tamasi P. Szabo M. Csongor J. DNA repair $\mathbb{N}$ and UV light sensitivity of the lymphocytes in discoid lupus erythematosus. Studia Biophysica (Berlin) 1975; 50: 1-6.

3 Beighlie D J, Teplitz R L. Repair of UV damaged DNA in N systemic lupus erythematosus. J Rheumatol 1975: 2: 149-60.

4 Harris G, Asbery L, Lawley P D, Denman A M. Hylton W. Defective repair of $O^{6}$-methylguanine in autoimmune diseases. Lancet 1982; ii: 952-6.

5 Bloom D. Congenital telangiectatic erythema resembling lupus erythematosus in dwarfs. Am J Dis Child 1954; 88: 754-8.

6 Taniguchi N, Mukai M, Nagaoki T, et al. Impaired B-cell $\frac{T}{T}$ differentiation and T-cell regulatory function in four patients with Bloom's syndrome. Clin Immunol Immunopathol 1982; 22: 247-58. 
7 Waldmann T A. Immunological abnormalities in ataxia telangiectasia. In: Bridges B A, Harnden D G, eds. Ataxiatelangiectasia. A cellular and molecular link between cancer, neuropathology and immune deficiency. Chichester: Wiley, 1982: 37-51.

8 Pedersen F K, Hertz H. Lundsteen C, Platz P, Thomsen M. Indication of primary immune deficiency in Fanconi's anemia. Acta Paediatr Scand 1977; 66: 745-51.

9 Chaganti R S K, Schonberg S, German J. A manyfold increase in sister chromatid exchanges in Bloom's syndrome lymphocytes. Proc Natl Acad Sci USA 1974; 71: 4508-12.

10 Ved Brat S. Sister chromatid exchange and cell cycle in fibroblasts of Bloom's syndrome. Hum Genet 1979; 48: 73-9.

11 Shiraishi Y, Freeman A I, Sandberg A A. Increased sister chromatid exchange in bone marrow and blood cells from Bloom's syndrome. Cytogenet Cell Genet 1976; 17: 162-73.

12 Krepinsky A B, Gingerich J, Heddle J A. Further evidence for the hypersensitivity of Bloom syndrome cells to ethylating agents. In: Bora K C, et al. eds. Progress in mutation research. vol 3. Amsterdam: Elsevier, 1982.

13 Wolff S, Rodin B, Cleaver J E. Sister chromatid exchanges induced by mutagenic carcinogens in normal and xeroderma pigmentosum cells. Nature 1977; 265: 347-9.

14 Miura K, Morimoto K, Kolzumi A. Proliferative kinetics and mitomycin C-induced chromosome damage in Fanconi's anaemia lymphocytes. Hum Genet 1983; 63: 19-23.

15 Taylor A M R, Rosney C M, Campbell J B. Unusual sensitivity of ataxia telangiectasia cells to bleomycin. Cancer Res 1979; 39: 1046-50.

16 Cunliffe P N, Mann J R, Cameron A H, Roberts K D, Ward H W C. Radiosensitivity in ataxia-telangiectasia. Br J Radiol 1975; 48: $374-6$.

17 Tuschl H, Kovac R, Wolf A, Smolen J S. SCE frequencies in lymphocytes of systemic lupus erythematosus patients. Mutat Res 1984; 128: 167-71.

18 Palmer R G, Doré C J, Henderson L, Denman A M. Sister chromatid exchange frequencies in fibroblasts and lymphocytes of patients with systemic lupus erythematosus. Mutat Res (in press).

19 Tan E M, Cohen A S, Fries J F. The 1982 revised criteria for the classification of systemic lupus erythematosus. Arthritis Rheum 1982; 25: 1271-7.

20 Goto K, Maeda S, Kano Y, Sugiyama T. Factors involved in differential giemsa-staining of sister chromatids. Chromosoma 1978; 66: 351-9.

21 Perry P, Wolff S. New giemsa method for the differential staining of sister chromatids. Nature $1974 ; 251$ : 156-8.

22 Palmer R G, Doré C J, Denman A M. Chlorambucil-induced chromosome damage to human lymphocytes is dose dependent and cumulative. Lancet 1984; i: 246-9.

23 Snedecor G W, Cochran, W G. Statistical methods. 6th ed. Iowa: State University Press, 1967: 331-7.

24 Goth-Goldstein R. Repair of DNA damaged by alkylating carcinogens is defective in xeroderma pigmentosum-derived fibroblasts. Nature 1977; 267: 81-2.

25 Zamansky G B, Minka D F, Deal C L, Hendricks K. The in vitro photosensitivity of systemic lupus erythematosus skin fibroblasts. J Immunol 1985; 134: 1571-6.

26 Solomon E, Bobrow M. Sister chromatid exchanges-a sensitive assay of agents damaging human chromosomes. Mutat Res 1975; 30: 273-8.

27 Davidson R L, Kaufman E R, Dougherty C P, Ouellette A M, DiFolco $C M$, Latt $S A$. Induction of sister chromatid exchanges by BUdR is largely independent of the BUdR content of DNA. Nature 1980; 284: 74-6.

28 Abe S, Sasaki M. Chromosome aberrations and sister chromatid exchanges in chinese hamster ovary cells exposed to various chemicals. J Natl Cancer Inst 1977; 58: 1635-41.

29 Oikawa A, Sakai S, Horaguchi K, Tohda H. Sensitivities of peripheral lymphocytes from healthy humans to induction of sister chromatid exchanges by chemicals. Cancer Res 1983; 43: $439-42$. 